Running head: SOCIAL SUPPORT AND PERFORMANCE

Please reference this paper as:

Rees, T., \& Freeman, P. (2010). The effect of experimentally provided social support on golf-putting performance. The Sport Psychologist, 18, 333-348.

Social Support and Performance in a Golf-Putting Experiment

Tim Rees and Paul Freeman

University of Exeter, UK

Submitted: $1^{\text {st }}$ July 2009

Resubmitted: $6^{\text {th }}$ November 2009

$2^{\text {nd }}$ resubmission: $17^{\text {th }}$ February 2010

Author notes

Tim Rees and Paul Freeman, School of Sport and Health Sciences.

Correspondence concerning this article should be addressed to Tim Rees, School of Sport and Health Sciences, University of Exeter, St. Luke's Campus, Heavitree Road, Exeter EX1 2LU, UK. E-mail tim.j.rees@exeter.ac.uk. Telephone: +44 1392 264722. Fax: +44 1392 264726. 


\section{Social Support and Performance in a Golf-Putting Experiment}

Submitted: $1^{\text {st }}$ July 2009

Resubmitted: $6^{\text {th }}$ November 2009

$2^{\text {nd }}$ resubmission: $12^{\text {th }}$ February 2010 


\begin{abstract}
This study examined the impact of a social support manipulation on performance. Participants with high and low levels of perceived support were randomly assigned to an experimental support or control condition, prior to completing a golf-putting task. Participants with high levels of perceived support performed at a higher level than those with low levels of perceived support. Participants in the support condition performed at a higher level than those in the control condition. A significant interaction was primarily attributable to the low perceived support participants in the support condition performing better than the low perceived support participants in the control condition. Participants in the support condition also experienced less frequent and distracting task-irrelevant thoughts compared to those in the control condition. These results suggest that experimentally manipulated support may lead to improvements in the performance of novices completing a golf-putting task, and that such support may be particularly important for those low in perceived support.
\end{abstract}


Social Support and Performance in a Golf-Putting Experiment

Considerable evidence suggests that individuals with supportive relationships experience favorable outcomes (Cohen \& Wills, 1985), including better mental health and well-being (for a review, see, e.g., Cohen, Underwood, \& Gottlieb, 2000). Associations have also been observed between social support and physiological processes, physical disease, and mortality (Cohen, 1988; Uchino, Cacioppo, \& Kiecolt-Glaser, 1996). Increased awareness of its potential within sport (Holt \& Hoar, 2006; Rees, 2007) has led to recent work demonstrating links between social support and self-confidence (Rees \& Freeman, 2007), processes underpinning performance (Rees \& Hardy, 2004), and objective performance outcome (e.g., Rees \& Freeman, 2009; Rees, Hardy, \& Freeman, 2007). Although the evidence linking social support to performance is still relatively scarce, it has been demonstrated that social support may account for as much as $24 \%$ of the variance in performance, over and above effects of stress (Rees et al., 2007; Rees \& Freeman, 2009). Understanding the role of social support within performance contexts is therefore important both for researchers and practitioners. A solid foundation of theory-led research could help to guide the development of social support interventions.

Although variously defined (Veiel \& Baumann, 1992), social support is comprised of three major sub-constructs (Lakey, in press). Social integration (a structural form of support) reflects the number of different types of relationships in which recipients participate. Perceived support (a functional form of support) refers to one's potential access to social support and is a support recipient's subjective judgment that friends, family, team-mates, and coaches would provide assistance if needed. Enacted support (a functional form of support) reflects the specific helping actions provided by friends, family, team-mates, and coaches, usually during a specific time frame. Enacted support may be assessed via objectively observable effortful supportive behaviors (Burleson, 2009; Burleson \& MacGeorge, 2002; Shumaker \& Brownell, 1984; 
Vangelisti, 2009), or via self-reported receipt of the type or amount of enacted support (often termed received support ${ }^{1}$ ).

Generally, it is people's perception of their social support that has been noted as crucial for their mental health and emotional well-being (Cohen, 1988; Cohen, Gottlieb, \& Underwood, 2000; Cohen \& Wills, 1985; Wills \& Shinar, 2000). On the other hand, evidence for the benefits of self-reported enacted ${ }^{2}$ support is mixed (Uchino, 2009) - such support is either associated with a beneficial effect, no effect, or even a detrimental effect on outcomes (e.g., Reinhardt, Boerner, \& Horowitz, 2006). The research literature in sport provides evidence for the benefits of both perceived and self-reported enacted support in relation to performance (e.g., see Freeman \& Rees, 2008). Although there is evidence in sport that athletes' social support interactions are sometimes viewed as more negative than positive (Udry Gould, Bridges, \& Tuffey, 1997), the importance of support has been implicated in relation to dealing with competitive stress (Crocker, 1992), slumps in performance (Madden, Kirkby, \& McDonald, 1989), and burn-out (Gould, Tuffey, Udry, \& Loehr, 1996). The recommendations from the sport psychology literature are that sportspeople should be encouraged to be proactive in harnessing social support from those around them (Richman, Hardy, Rosenfeld, \& Callanan, 1989).

Given the empirical evidence for the impact of self-reported enacted support, for researchers and practitioners alike, knowledge is needed about the impact upon performance of actual support exchanges. In a recent intervention study (Freeman, Rees, \& Hardy, 2009), golfers were provided with support though a focused professionally-led intervention (cf. Hogan, Linden, \& Najarian, 2002), instigated after a baseline period. An overall performance improvement was noted, alongside self-reported increases in enacted support. Performance improvements were not, however, statistically significant for all golfers. It might be that the impact of the supportive intervention would have been more effective still, had the golfers' initial levels of perceived 
support been taken into account. In other words, in understanding the links between social support and key outcomes, it could be important to take account of both enacted and perceived support simultaneously (Bianco \& Eklund, 2001; Dunkel-Schetter \& Bennett, 1990; Freeman \& Rees, 2008). Low perceived support is generally correlated with psychological distress and is a vulnerability factor for poor health (Cohen, Gottlieb, \& Underwood, 2000). Those with the lowest levels of perceived support may therefore be most at risk, and it is those individuals who may benefit the most from enacted support (Uchino, 2009).

The above discussion raises the question as to what the consequences of enacted support would be for individuals with low versus high perceived support. As Uchino (2009) noted, very little research has examined this interaction of perceived and enacted support, perhaps due to the conceptual overlap between the two constructs. Although perceived and enacted support are considered two key but separate constructs (Dunkel-Schetter \& Bennett, 1990; Helgeson, 1993; Wethington \& Kessler, 1986), they are conceptually related under some conditions and may interact in potentially important ways (Uchino, 2009), and influence each other in some contexts (e.g., Haber, Cohen, Lucas, \& Baltes, 2007). For example, enacted support can influence perceptions of support, especially during stressful events (e.g., natural disasters) that influence one's social network (Norris \& Kaniasty, 1996).

The primary purpose of the present study was therefore to attempt to elucidate whether the impact of enacted support via experimental manipulation would be the same for all individuals, or whether the impact might differ dependent on whether individuals have high or low levels of perceived support. The effectiveness of enacted support may also depend on the context in which it is provided, with beneficial influences more likely when there is a match between the type of enacted support and the context (Berg \& Upchurch, 2007). In the present study, the experimental manipulation entailed a focus on emotional and esteem forms of enacted 
support, both noted as useful in a range of situations (Cohen \& Wills, 1985), including in relation to confidence and performance (e.g., Freeman, \& Rees, 2009; Rees \& Freeman, 2007; Rees et al., 2007). Such forms of support may be considered more nurturing, less obtrusive, less controlling, and less likely to undermine self-efficacy than informational (e.g., direct advice) and tangible (e.g., concrete instrumental assistance) forms of support (Bolger \& Amarel, 2007; Trobst, 2000). This is because the receipt of informational and tangible support could undermine recipients' belief in their skills and competence to perform well in the absence of such help or advice.

There have been numerous calls to examine mechanisms linking social support to outcomes (Lakey \& Cohen, 2000), and examining enacted support in conjunction with perceived support should aid in understanding when enacted support is effective. To further develop understanding, research should also examine if the social support-performance relationship is mediated by psychological states (Cohen, Gottlieb, \& Underwood, 2000). With this in mind, a secondary purpose was to examine one potential mechanism linking social support to performance: cognitive interference. When concentration suffers as a result of self-generated task-irrelevant thoughts, performance deteriorates (Hatzigeorgiadis \& Biddle, 2000; Sarason, Pierce, \& Sarason, 1996). Low levels of social support are associated with more cognitive interference (Sarason, Levine, Basham, \& Sarason, 1983; Sarason \& Sarason, 1986), potentially because those with low levels of support may feel under greater stress and thus worry more (e.g., over their ability to accomplish assigned tasks) or attempt to distract themselves with off-task thoughts. Enacted support should, on the other hand, help these individuals to focus their attention more completely on the task at hand rather than on self-preoccupying thoughts. Sarason and Sarason (1986) noted effects for both perceived and enacted support in relation to cognitive interference during an academic task. Specifically, they noted that their experimental 
manipulation of support reduced cognitive interference, especially for those with low levels of perceived support. As Sarason, Sarason and Pierce (1990) noted, in the context of sport, support "may enable a sports competitor to be more task-focused and to reduce extraneous thoughts that interfere with performing the task" (p. 123). In the present study, we expected that participants' social support would be associated with less cognitive interference. This in turn would be related to enhanced task performance.

We hypothesized the following key effects: a) interactions for perceived support and the experimental manipulation. Specifically, we expected that those low in perceived support but in the support condition would perform better and experience lower cognitive interference than those low in perceived support and in a control condition; and b) that cognitive interference would mediate effects of perceived and experimentally manipulated support on performance.

\section{Method}

\section{Participants and Design}

Participants were a sample of 80 (42 female, 38 male; mean age 19.48, SD 1.85 years) sport and health science undergraduate students. These participants were drawn from an initial convenience sample of 184 (93 female, 91 male; mean age 19.92, SD 1.30 years) participants who completed a questionnaire to assess perceived support. From this initial sample, and in order to create two clear sets of high and low perceived support participants, those with the highest $(n$ =40: 25 female, 15 male) and lowest $(n=40: 17$ female, 23 male) perceived support scores were recruited to the full experiment. The study had a two-factor design, with two levels to each factor (perceived support: high, low; manipulation: support, control). All participants had either very little experience or no experience of golf-putting.

\section{Materials}


The experiment consisted of a golf-putting task completed in a laboratory. The equipment consisted of an artificial indoor putting green, at one end of which was a target divided into 10 evenly spaced concentric circles. The centre of the target was four inches in diameter; the remainder were 4 inches apart.

\section{Procedure}

The study was approved by an institutional ethics committee review, and participants provided informed consent. The experimenters were two postgraduate sport and health science students ( 1 male; 1 female). The male experimenter administered the basic instructions and scored the putting task; the female experimenter administered the support manipulation and the measures (see below). Prior to entering the laboratory, participants in either the high perceived support group $(n=40)$ or the low perceived support group $(n=40)$ were randomly assigned to an experimental support condition or a control condition. Thus, there were 20 participants in each of four conditions: a) low perceived support / support condition, b) low perceived support / control condition, c) high perceived support / support condition, and d) high perceived support / control condition. Independent samples t-tests demonstrated that there was no significant difference between the perceived support scores of those in the low perceived support / support condition and those in the low perceived support / control condition, $t_{38}=.34, p=.74$. Similarly, there was no significant difference between the perceived support scores of those in the high perceived support / support condition and those in the high perceived support / control condition, $t_{38}=.17$, $p=.87$. The two experimenters were blind to whether the participants had previously scored high or low on perceived support. This was achieved by a third researcher (the lead author) establishing the high and low perceived support groups. Participants were blind to the purpose of the study. Participants were instructed from a standardized script that the nature of the study was to understand about task performance under experimental conditions, followed by an explanation 
of the golf-putting task and its scoring system. Participants were then informed that their scores and initials would be recorded on both an overall score chart and a leaderboard, available for all other participants to view, and that they would be asked to complete some measures following their performance. All participants were, in fact, shown the same standardized score chart and leaderboard, which contained 20 false scores ranging from 20 to 70 with a mean of $46.75(\mathrm{SD}=$ 12.42).

In addition to the basic instructions, participants in the support condition were given the following script, designed to convey aspects of emotional and esteem support, and using similar statements to those used in former studies into the impact of experimentally manipulated support on performance (cf. Sarason \& Sarason, 1986). The first two sentences of the script focused on esteem support (i.e., bolstering a person's sense of competence or self-esteem: Cutrona \& Russell, 1990; Rees \& Hardy, 2000); the last sentence focused on emotional support (i.e., being “there” for the person: Cutrona \& Russell, 1990; Rees \& Hardy, 2000).

As a sport and health science student, you are a very capable sportsperson and we fully believe that you will be able to execute this task successfully. Just relax, take your time, and we are confident you will perform very well. We will be here throughout the task, so please feel free to ask for our help at any time, and we are very happy to provide advice and feedback if you wish, and we will be happy to discuss any questions or concerns that you may have now, during the task, or afterwards.

Pilot work had shown that participants do not seek out the experimenter for help, and in the present study, no participant sought out the experimenter for help.

On completion of the golf-putting task, participants were asked to fill out the Thought Occurrence Questionnaire for Sport (Hatzigeorgiadis \& Biddle, 2000) and a manipulation check, whilst their individual total scores were recorded. Participants were then provided with 
additional feedback explaining the nature and purpose of the task and were offered the opportunity to ask any (further) questions.

\section{Measures}

Perceived support. Perceived support was assessed by way of 20 items, adapted from the questionnaire used by Freeman and Rees (2009) to measure multidimensional social support. As Freeman and Rees used high-level golfers in their study, some of the items were re-worded to fit the more general sample in the present study. This followed two recommendations from the social support literature: a) social support measures should be relevant to the situational context in which they are being used; and b) social support researchers should write new items to capture specific aspects of the support needs of the target population (Bianco \& Eklund, 2001; House \& Kahn, 1985; Wills \& Shinar, 2000). Sample items included "is always there for you” (emotional), “encourages you" (esteem), "gives you moral support” (emotional), and "tells you, you can do it" (esteem). Participants were asked "To what extent do you have someone who ... ," with response options ranging on a 5-point scale from 1 (not at all) to 5 (a lot). Overall scores could therefore range from 20-100. The Cronbach's alpha internal consistency reliability coefficient for this index of perceived support was $\alpha=.93$ using data from the original 184 participants, and was $\alpha=.95$ for the 80 participants in the experimental study.

Performance. Performance comprised ten putts towards the target from a distance of ten feet. The centre of the target was worth 10 points, and the outer rim was worth 1 point. Putts outside this target were awarded a score of zero. Performance scores could therefore range from $0-100$.

Cognitive interference. To assess cognitive interference, we used the Thought Occurrence Questionnaire for Sport (TOQS: Hatzigeorgiadis \& Biddle, 2000). The validity of the TOQS for measuring interfering thoughts in sport has been supported by previous studies (Lane, Harwood, 
\& Nevill, 2005; Hatzigeorgiadis \& Biddle, 2000). The TOQS comprises 17 items, designed to assess task-irrelevant thoughts during sports performance. Sample items included "During the task I had thoughts that I want to quit," "During the task I had thoughts that I do not want to take part in this task anymore," and "During the task I had thoughts that I am not going to perform as well as others". For each item, participants were requested to: (a) rate (on a scale from $1=$ never to $7=$ very often) how frequently they experienced a thought (Frequency); (b) rate (on a scale from $1=$ not at all to $7=$ very distracting) how distracting these thoughts were (Distraction); and (c) rate (on a scale from - 3 = made me give up trying to $3=$ made me try harder) how this thought affected the amount of effort they put into completing the task (Effort). The Cronbach's alpha internal consistency reliability coefficients for the three scales using data from the present study were: Frequency $\alpha=.83$, Distraction $\alpha=.83$, Effort $\alpha=.69$.

Manipulation check. To assess whether participants believed they were in the support or control conditions, we asked the following question, "To what extent did you feel supported during the task?" Participants responded on a $1-7$ scale (from $1=$ not at all to $7=$ very $m u c h$ so).

Analyses. The study entailed the use of 2 (perceived support: high, low) by 2 (manipulation: support, control) between-groups analyses of variance on the scores in the golfputting task and the TOQS scores. To examine whether support affected performance through cognitive interference, a series of mediation analyses was conducted.

\section{Results}

Descriptive Statistics. The mean score for perceived support for the initial sample of 184 participants was $66.54(\mathrm{SD}=13.11$, Median $=67.50)$. Those 40 participants with the highest (range 75-99) and lowest (range 26-57) perceived support scores were subsequently requested to participate in the golf-putting task. For those 80 participants in the experimental study, means, 
standard deviations and intercorrelations for perceived support, the manipulation check, the TOQS subscales, and golf-putting scores are in Table 1. Data were screened for missing values, of which there were none. For the analyses of variance, data met the assumptions of normality and homogeneity of variance across cells.

Manipulation check. Compared to those in the control condition $(M=2.33, S D=1.59)$, those in the support condition $(M=4.55, S D=1.36)$ reported that they felt more supported during the golf-putting task $\left(t_{78}=6.73, p<.001\right)$.

Performance. Means and standard deviations of golf-putting scores as a function of perceived support and the experimental condition are in Table 2. Participants with high levels of perceived support performed at a higher level $(M=50.95, S D=13.48)$ than did those with low levels of perceived support $(M=44.75, S D=12.94), F_{1,76}=5.50, p=.02, \eta_{p}{ }^{2}=.07$. Participants in the support condition performed at a higher level $(M=52.73, S D=10.28)$ than did those in the control condition $(M=42.98, S D=14.64), F_{1,76}=13.60, p<.01, \eta_{p}{ }^{2}=.15$. There was a significant interaction (see Figure 1) between perceived support and the experimental manipulation $\left(F_{1,76}=7.73, p<.01, \eta_{p}{ }^{2}=.09\right)$. This interaction demonstrated a) a significant difference between the low perceived support participants who were in the support condition $(M$ $=53.30, S D=8.92)$ and those who were in the control condition $(M=36.20, S D=10.49)$; and b) no significant difference between the high perceived support participants who were in the support condition $(M=52.15, S D=11.69)$ and those who were in the control condition $(M=$ 49.75, $S D=15.27)$.

Cognitive interference. Means and standard deviations of TOQS scale scores as a function of perceived support and the experimental condition are in Tables 3-5. There was no significant difference in the scores of participants rated as high or low on perceived support in relation to the TOQS scales $\left(F \mathrm{~s}_{1,76}=1.15-2.92, p \mathrm{~s}=.09-.29, \eta_{p}{ }^{2} \mathrm{~s}=.02-.04\right)$. Participants in 
the support condition experienced less frequent task-irrelevant thoughts $(M=1.82, S D=.50)$ compared to those in the control condition $(M=2.23, S D=.70), F_{1,76}=9.36, p<.01, \eta_{p}{ }^{2}=.11$, and less distracting task-irrelevant thoughts $(M=1.62, S D=.46)$ compared to those in the control condition $(M=1.98, S D=.65), F_{1,76}=8.39, p<.01, \eta_{p}{ }^{2}=.10$, but there was no difference in relation to effort $\left(F_{1,76}=.10, p<.75, \eta_{p}{ }^{2}=.00\right)$. There were no significant interactions $\left(F \mathrm{~s}_{1,76}=.23-.41, p \mathrm{~s}=.52-.63, \eta_{p}{ }^{2} \mathrm{~s}=.00-.01\right)$.

\section{Mediation Analysis}

The tests of mediation followed the principles of Baron and Kenny (1986). To establish mediation, there must be a significant relationship between the mediator and the independent variable, but when the dependent variable is regressed on both the mediator and independent variable, a previously significant relationship between the independent and dependent variables should be significantly reduced and (for full mediation) be rendered non-significant. In this study, the main effects (of perceived support and the experimental manipulation) and the interaction were significant in relation to performance. However, only the experimental manipulation was significant in relation to the mediator (cognitive interference Frequency and Distraction). The tests of mediation therefore only incorporated the relationships between the experimental manipulation and cognitive interference. This involved (a) regressing the mediator (cognitive interference) on the independent variable (experimental manipulation), (b) regressing the dependent variable (performance) on the independent variable (experimental manipulation), and (c) regressing the dependent variable (performance) on both the independent variable (experimental manipulation) and the mediator (cognitive interference).

Relevant statistics are presented in Table 6. From these it is apparent that (a) when performance was regressed upon the experimental manipulation and cognitive interference (Frequency) simultaneously, the relationship between the experimental manipulation and 
performance was not significantly reduced (by Sobel's test, Preacher \& Leonardelli, 2001; $z=$ $1.26, p=.21$ ), and (b) when performance was regressed upon the experimental manipulation and cognitive interference (Distraction) simultaneously, the relationship between the experimental manipulation and performance was not significantly reduced $(z=-.04, p=.97)$. In both cases, the relationship between the experimental manipulation and performance remained significant.

Overall, these results suggest that cognitive interference did not mediate the relationship between the experimental manipulation and performance.

\section{Discussion}

The results of the present study suggest that experimentally manipulated support may influence the performance of novices on a golf-putting task, and that this support may be particularly salient for those with low perceived support. The significant interaction demonstrated that for those with high perceived support, the experimental manipulation did not differentially affect performance. It was those low in perceived support whose performances were particularly sensitive to the experimental manipulation. In this study, we also assessed one potential mechanism for these effects: cognitive interference. The results revealed that participants in the support condition reported less frequent and distracting task-irrelevant thoughts. There was no effect for perceived support and no interaction in relation to cognitive interference. A mediation analysis suggested that cognitive interference played no role in mediating the effect of the experimental manipulation on performance. In the present study, therefore, although the experimental manipulation was related to cognitive interference, cognitive interference could not be regarded as a mechanism underpinning the impact of the experimental manipulation on performance.

The results of this experimental study add to the growing evidence from field studies linking perceived and enacted support with performance (e.g., Freeman \& Rees, 2008; Rees \& 
Freeman, 2009; Rees et al., 2007). These field studies have highlighted some of the supportive behaviors that might prove to be useful in applied settings, but they do not allow inferences to be made with regard to the efficacy of actual support exchanges. Freeman et al. (2009) did provide evidence for the benefits of a social support intervention with three high-level golfers; the present study takes this a step further, demonstrating the effects of manipulating support in an experimental setting.

In the present study, we also assessed cognitive interference, an important mechanism underpinning performance disruptions (Hatzigeorgiadis \& Biddle, 2000; Sarason et al., 1996). Social support may reduce cognitive interference by enabling athletes to be more task-focused and by reducing extraneous thoughts that interfere with performing the task (Sarason et al., 1990). Sarason and Sarason (1986) found that both perceived support and an experimental manipulation of support (and their interaction) influenced the cognitive interference (and performance) of participants undertaking an academic task. In the present study, we only observed effects for the experimental manipulation in relation to cognitive interference, and cognitive interference did not mediate the experimental manipulation-performance effect. The golf-putting task may have been less sensitive to creating cognitive interference in comparison with a more cognitively-demanding task. Despite these inconsistent findings, it would still be important for researchers to endeavor to identify potential mechanisms underpinning social support effects (Cohen, 1988; Cohen, Gottlieb, \& Underwood, 2000; Lakey \& Cohen, 2000; Saltzman \& Holahan, 2002; Schwarzer \& Leppin, 1991; Thoits, 1995). The social support literature may still be characterized by its lack of empirical evidence for the specific psychological mechanisms through which social support operates. Cognitive interference may be one such mechanism, but theoretically, social support may lead to a host of positive cognitive, 
emotional, behavioral, and physiological states, which in turn lead to better outcomes (Cohen, Gottlieb, \& Underwood, 2000).

Various interventions have been used to increase social support and improve healthrelated outcomes such as depression, weight loss, and blood pressure (see Hogan et al., 2002). Although these interventions differ in the specific activities they involve and the outcomes they aim to influence, they are linked by their focus on mobilizing the social environment or altering an individual's attitude towards it (Gottlieb, 2000). Our results suggest that the supportive manipulation was successful both in differentiating performance scores and in differentiating cognitive interference. These findings should not, however, be interpreted as evidence that all support attempts will have uniformly beneficial effects on performance across all participants. In fact, the main effect of the experimental manipulation is qualified by the significant interaction. That is, our results are consistent with the suggestions of Uchino (2009) that it is in particular those people who report relatively low levels of perceived support for whom the supportive exchanges are facilitative. This support does not seem to be of significant benefit to those who are already high in perceived support. The mixed evidence for enacted support in previous studies might be because these studies failed to take into account existing levels of perceived support. Low perceived support is correlated with psychological distress and is a vulnerability factor for poor health. As the most at risk, it may be precisely these people, low in perceived support, who will benefit from support-based interventions.

The key applied implication of this study is that even a brief social support intervention may positively influence performance. In general social psychology, comprehensive support interventions that address various support needs are generally more effective than interventions with a narrow focus (Eckenrode \& Hamilton, 2000). As we noted in the introduction to this paper, the focus of the experimental manipulation in this study was on emotional and esteem 
forms of support. These types of support have been noted as useful in a range of situations (Cohen \& Wills, 1985), including in relation to confidence and performance (e.g., Freeman, \& Rees, 2009; Rees \& Freeman, 2007; Rees et al., 2007). We should note, however, that additional factors may influence the effectiveness of social support exchanges. For example, some authors have suggested the importance of contextual factors, such as the match between the type of support provided and the needs of the individual (Cutrona \& Russell, 1990). Tied more specifically to stress-buffering models (not examined in the present study), the "optimal matching" model predicts that support will be more effective when it is matched to the needs arising from a stressful event. Although the optimal matching model offers an eloquent explication of when stress-buffering is likely to occur, it has received little empirical support (Burleson, 2003; Burleson \& MacGeorge, 2002). Instead, the same supportive behavior often serves multiple functions, and different supportive behaviors can achieve similar objectives (Burleson \& MacGeorge, 2002; Viswesvaran, Sanchez, \& Fisher, 1999). There is frequently a high degree of overlap between types (dimensions) of support in naturalistic settings (Cohen \& Wills, 1985), such that attempts to bolster a person's sense of competence (esteem support) may also be interpreted as a sign of caring (emotional support).

A key strength of the present study was the clear performance effect due to the interaction of perceived support and the experimental manipulation. This was similar to the study of Sarason and Sarason (1986), who used the same sample size with participants undertaking an academic task. Some potential methodological limitations of the present study should, however, be noted. First, it could be of concern that our support and control conditions were not equivalently exposed to a script - one inert and one containing the causal factor - and hence participants in the experimental group were treated differently from those in the control condition. Second, because the social support manipulation included esteem support (bolstering a person's sense of 
competence), there is a possibility that the experimenter's expression of confidence that participants would do well on the task was confounded with expectancy effects. Third, our task entailed putting to a target on which the ball needed to stop rather than attempting to hole a putt. Thus, although we can discuss social support effects in terms of performance on this task, one should be cautious in making inferences about golf-putting in real life. Fourth, we used a similar sampling strategy to that of Sarason and Sarason (1986), drawing our experimental sample from a wider pool of participants who had already filled out the measure of perceived support. However, given our focus on those with low and high levels of perceived support, we cannot make inferences regarding those with moderate amounts of support. Finally, although this study's performance effects are notable, the brevity of the social support manipulation could potentially represent a threat to ecological validity. Administered on one occasion by an experimenter with only minimal rapport and no prior relationship with the participants, such an intervention is perhaps not typical of most support interactions in the real world.

The results of the present study suggest that the negative effects of a lack of perceived support can be countered by focused interventions. In light of the present results, future studies are needed of the roles of perceived and enacted support in situations different from and more complex than the one used in this study. For example, for certain stressful tasks, perhaps involving greater decision-making and/or greater consequences (e.g., a group's performance being dependent on the success or otherwise of an individual), those low in perceived support might have vulnerabilities that would decrease their chances of success. The results of this study suggest that if low perceived support is a vulnerability factor, it is one for which targeted interventions could play a beneficial role. 


\section{References}

Baron, R. M., \& Kenny, D. A. (1986). The moderator-mediator variable distinction in social psychological research: Conceptual, strategic, and statistical considerations. Journal of Personality and Social Psychology, 51, 1173-1182.

Barrera, M., Jr. (1986). Distinctions between social support concepts, measures, and models. American Journal of Community Psychology, 14, 413-445.

Berg, C. A., \& Upchurch, R. (2007). A developmental-contextual model of couples coping with chronic illness across the lifespan. Psychological Bulletin, 133, 920-954.

Bianco, T., \& Eklund, R. C. (2001). Conceptual considerations for social support research in sport and exercise settings: The case of sport injury. Journal of Sport \& Exercise Psychology, 23, 85-107.

Bolger, N., Zuckerman, A., \& Kessler, R. C. (2000). Invisible support and adjustment to stress Journal of Personality and Social Psychology, 79, 953-961.

Bolger, N., \& Amarel, D. (2007). Effects of social support visibility on adjustment to stress: Experimental evidence. Journal of Personality and Social Psychology, 92, 458-475.

Burleson, B. R. (2003). Emotional support skill. In J. O. Greene \& B. R. Burleson (Eds.), Handbook of communication and social interaction skills (pp. 551 - 594). Mahwah, NJ: Erlbaum.

Burleson, B. R. (2009). Understanding the outcomes of supportive communication: A dualprocess approach. Journal of Social and Personal Relationships, 26, 21-38.

Burleson, B. R., \& MacGeorge, E. L. (2002). Supportive communication. In M. L. Knapp \& J. A. Daly (Eds.), Handbook of interpersonal communication (pp. 374 - 424). Thousand Oaks, CA: Sage. 
Cohen, S. (1988). Psychosocial models of the role of social support in the etiology of physical disease. Health Psychology, 7, 269-297.

Cohen, S., Gottlieb, B. H., \& Underwood, L. G. (2000). Social relationships and health. In S. Cohen, L. G. Underwood, \& B. H. Gottlieb (Eds.), Social support measurement and intervention: A guide for health and social scientists (pp. 3-25). New York: Oxford University Press.

Cohen, S., Underwood, L. G., \& Gottlieb, B. H. (2000). Social support measurement and intervention: A guide for health and social scientists. New York: Oxford University Press.

Cohen, S., \& Wills, T. A. (1985). Stress, social support and the buffering hypothesis. Psychological Bulletin, 98, 310-357.

Crocker, P. R. E. (1992). Managing stress by competitive athletes: Ways of coping. International Journal of Sport Psychology, 23, 161-175.

Cutrona, C. E., \& Russell, D. W. (1990). Type of social support and specific stress: Toward a theory of optimal matching. In B. R. Sarason, I. G. Sarason, \& G. R. Pierce (Eds.), Social support: An interactional view (pp. 319 -366). New York: Wiley.

Dunkel-Schetter, C., \& Bennett, T. L. (1990). Differentiating the cognitive and behavioral aspects of social support. In B. R. Sarason, I. G. Sarason and G. R. Pierce (Eds.), Social support: An interactional view (pp. 267-296). New York: Wiley.

Eckenrode, J., \& Hamilton, S. (2000). One-to-one support interventions. In S. Cohen, L. G. Underwood \& B. H. Gottlieb (Eds.), Social support measurement and intervention: A guide for health and social scientists (pp. 246-277). New York: Oxford University Press. 
Freeman, P., \& Rees, T. (2008). The effects of perceived and received support on objective performance outcome. European Journal of Sport Sciences, 8, 359-368.

Freeman, P., \& Rees, T. (2009). How does perceived support lead to better performance? An examination of potential mechanisms. Journal of Applied Sport Psychology, 21, 429-441.

Freeman, P., Rees, T., \& Hardy, L. (2009). An intervention to increase social support and improve performance. Journal of Applied Sport Psychology, 21, 186-200.

Gottlieb, B. H. (2000). Selecting and planning support interventions. In S. Cohen, L. G. Underwood \& B. H. Gottlieb (Eds.), Social support measurement and intervention: A guide for health and social scientists (pp. 195-220). New York: Oxford University Press.

Gould, D., Tuffey, S., Udry, E., \& Loehr, J. (1996). Burnout in competitive junior tennis players: II: Qualitative analysis. The Sport Psychologist, 10, 341-366.

Haber, M. G., Cohen, J. L., Lucas, T., \& Baltes, B. B. (2007). The relationship between selfreported received and perceived social support: A meta-analytic review. American Journal of Community Psychology, 39, 133-144

Hatzigeorgiadis, A., \& Biddle, S. J. H. (2000). Assessing cognitive interference in sport: development of the Thought Occurrence Questionnaire for Sport. Anxiety, Stress, and Coping, 13, 65-86.

Helgeson, V. S. (1993). Two important distinctions in social support: Kind of support and perceived versus received. Journal of Applied Social Psychology, 23, 825-845.

Hogan, B. E., Linden, W., \& Najarian, B. (2002). Social support interventions: Do they work? Clinical Psychology Review, 22, 381-440. 
Holt, N. L., \& Hoar, S. (2006). The multidimensional construct of social support. In S. Hanton \& S. Mellalieu (Eds.), Literature reviews in sport psychology (pp. 199-225). New York: Nova.

House, J. S., \& Kahn, R. L. (1985). Measures and concepts of social support. In S. Cohen, \& S. L. Syme (Eds.), Social support and health (pp. 83-108). New York: Academic.

Lakey, B. (in press). Social support: Basic research and new strategies for intervention. In J. E. Maddux \& J. P. Tangney (Eds.), Social psychological foundations of clinical psychology. New York: Guilford.

Lakey, B., \& Cohen, S. (2000). Social support theory and measurement. In S. Cohen, L. G. Underwood, \& B. H. Gottlieb (Eds.), Social support measurement and intervention: A guide for health and social scientists (pp. 29-52). New York: Oxford University Press.

Lane. A. M., Harwood, C., \& Nevill, A. M. (2005). Confirmatory factor analysis of the Thought Occurrence Questionnaire for Sport (TOQS) among adolescent athletes. Anxiety, Stress, and Coping, 18, 245- 254.

Madden, C. C., Kirkby, R. J., \& McDonald, D. (1989). Coping styles of competitive middle distance runners. International Journal of Sport Psychology, 20, 287-296.

Norris, F. H., \& Kaniasty, K. (1996). Received and perceived social support in times of stress: A test of the social support deterioration deterrence model. Journal of Personality and Social Psychology, 71, 498-511.

Preacher, K. J., \& Leonardelli, G. J. (2001). Calculation for the Sobel Test: An interactive calculation tool for mediation tests. http://www.unc.edu/ preacher/sobel/sobel.htm

Rees, T. (2007). Influence of social support on athletes. In S. Jowett \& D. Lavallee (Eds.), Social psychology in sport (pp. 223-231). Champaign, IL: Human Kinetics. 
Rees, T., \& Freeman, P. (2007). The effects of perceived and received support on selfconfidence. Journal of Sports Sciences, 25, 1057-1065.

Rees, T., \& Freeman, P. (2009). Social support moderates the relationship between stressors and task performance through self-efficacy. Journal of Social and Clinical Psychology, 28, 245-264.

Rees, T., Hardy, L., \& Freeman, P. (2007). Stressors, social support and effects upon performance in golf. Journal of Sports Sciences, 25, 33-42.

Reinhardt, J. P., Boerner, K., \& Horowitz, A. (2006). Good to have but not to use: Differential impact of perceived and received support on well-being. Journal of Social and Personal Relationships, 23, 117-129.

Richman, J. M., Hardy, C. J., Rosenfeld, L. B., \& Callanan, R. A. E. (1989). Strategies for enhancing social support networks in sport: A brainstorming experience. Journal of Applied Sport Psychology, 1, 150-159.

Saltzman, K. M., \& Holahan, C. J. (2002). Social support, self-efficacy, and depressive symptoms: An integrative model. Journal of Consulting and Clinical Psychology, 21, $309-322$.

Sarason, I. G., Levine, H. M., Basham, R. B., \& Sarason, B. R. (1983). Assessing social support: The Social Support Questionnaire. Journal of Personality and Social Psychology, 44, $127-344$.

Sarason, I. G., Pierce, G. R., \& Sarason, B. R. (1996). Domains of cognitive interference. In I. G. Sarason, G. R. Pierce, \& B. R. Sarason (Eds.), Cognitive interference: Theories, methods and findings (pp. 139-152). Mahwah, NJ: Erlbaum. 
Sarason, I. G., \& Sarason, B. R. (1986). Experimentally provided social support. Journal of Personality and Social Psychology, 50, 1222-1225.

Sarason, I. G., Sarason, B. R., \& Pierce, G. R. (1990). Social support, personality and performance. Journal of Applied Sport Psychology, 2, 117-127.

Schwarzer, R., \& Leppin, A. (1991). Social support and health: A theoretical and empirical overview. Journal of Social and Personal Relationships, 8, 99-127.

Shumaker, S. A., \& Brownell, A. (1984). Toward a theory of social support: Closing conceptual gaps. Journal of Social Issues, 40, 11-36.

Thoits, P. A. (1995). Stress, coping, and social support processes: Where are we? What next? Journal of Health and Social Behavior, (Extra Issue), 53-79.

Trobst, K. K. (2000). An interpersonal conceptualization and quantification of social support transactions. Personality and Social Psychology Bulletin, 26, 971-986.

Uchino, B. N. (2009). Understanding the links between social support and physical health. A life-span perspective with emphasis on the separability of perceived and received support. Perspectives on Psychological Science, 4, 236-255.

Uchino, B. N., Cacioppo, J. T., \& Kiecolt-Glaser, J. K. (1996). The relationship between social support and physiological processes: A review with emphasis on underlying mechanisms and implications for health. Psychological Bulletin, 119, 488-531.

Udry, E., Gould, D., Bridges, D., \& Tuffey, S. (1997). People helping people? Examining the social ties of athletes coping with burnout and injury stress. Journal of Sport and Exercise Psychology, 19, 368-395.

Vangelisti, A. L. (2009). Challenges in conceptualizing social support. Journal of Social and Personal Relationships, 26, 39-51. 
Veiel, H. O. F., \& Baumann, U. (1992). The many meanings of social support. In H. O. F. Veiel \& U. Baumann (Eds.), The meaning and measurement of social support (pp. 1-9). New York: Hemisphere.

Viswesvaran, C., Sanchez, J. I., \& Fisher, J. (1999). The role of social support in the process of work stress: A meta-analysis. Journal of Vocational Behavior, 54, 314-334.

Wethington, E., \& Kessler, R. C. (1986). Perceived support, Received support, and adjustment to stressful life events. Journal of Health and Social Behavior, 27, 78-89.

Wills, T. A., \& Shinar, O. (2000). Measuring perceived and received social support. In S. Cohen, L. G. Underwood, \& B. H. Gottlieb (Ed.), Social support measurement and intervention: A guide for health and social scientists (pp. 86-135). New York: Oxford University Press. 


\section{Footnotes:}

${ }^{1}$ Received support generally refers to the reported use or exchange of support resources (enacted support), assessed by self-report, such that Barrera (1986) proposed the term perceived-received support to describe such perceptions of support received.

${ }^{2}$ In the following discussion, we use the term enacted support, but it should be noted that the terms enacted and received support are used interchangeably in the social support literature. 
Table 1

Means, SD, and Intercorrelations of Perceived Support, Manipulation Check, TOQS Subscales, and Putting Score

\begin{tabular}{lrrrcccc} 
& Mean & SD & 1 & 2 & 3 & 4 & 5 \\
\hline 1. Perceived support & 65.51 & 18.84 & & & & & \\
2. Manipulation check & 3.99 & 1.14 & .06 & & & & \\
3. TOQS(Frequency) & 2.03 & .64 & -.15 & $-.24^{*}$ & & & \\
4. TOQS(Distraction) & 1.80 & .59 & -.07 & -.16 & $.89 * *$ & & \\
5. TOQS(Effort) & .58 & .36 & -.14 & .16 & .11 & .12 & \\
6. Putting score & 47.85 & 13.49 & .20 & $.40^{* *}$ & $-.26^{*}$ & -.11 & .08 \\
\hline
\end{tabular}

Note. $N=80{ }^{*}$ denotes correlation significant at .05 level (2-tailed)

** denotes correlation significant at .01 level (2-tailed)

Table 2

Mean (SD) Putting Score as a Function of Perceived Support and Experimental Condition Perceived Support

\begin{tabular}{cccc}
\cline { 3 - 4 } Condition & High & Low & Total \\
\hline Support & $52.15(11.69)$ & $53.30(8.92)$ & $52.73(10.28)$ \\
Control & $49.75(15.27)$ & $36.20(10.49)$ & $42.98(14.64)$ \\
Total & $50.95(13.48)$ & $44.75(12.94)$ & \\
\hline
\end{tabular}

Table 3

Mean (SD) TOQS (Frequency) Score as a Function of Perceived Support and Experimental Condition

\begin{tabular}{cccc} 
& & Perceived Support & \\
\cline { 3 - 3 } Condition & High & Low & Total \\
\hline Support & $1.75(.57)$ & $1.89(.41)$ & $1.82(.50)$ \\
Control & $2.07(.59)$ & $2.39(.78)$ & $2.23(.70)$ \\
Total & $1.91(.60)$ & $2.14(.67)$ & \\
\hline
\end{tabular}


Table 4

Mean (SD) TOQS (Distraction) Score as a Function of Perceived Support and Experimental Condition

Perceived Support

\begin{tabular}{cccc} 
Condition & High & Low & Total \\
\hline Support & $1.51(.44)$ & $1.72(.47)$ & $1.62(.46)$ \\
Control & $1.95(.65)$ & $2.01(.65)$ & $1.98(.65)$ \\
Total & $1.73(.59)$ & $1.87(.58)$ & \\
\hline
\end{tabular}

Table 5

Mean (SD) TOQS (Effort) Score as a Function of Perceived Support and Experimental Condition

Perceived Support

\begin{tabular}{cccc} 
Condition & High & Low & Total \\
\hline Support & $.49(.29)$ & $.65(.38)$ & $.57(.34)$ \\
Control & $.56(.30)$ & $.64(.46)$ & $.60(.38)$ \\
Total & $.53(.29)$ & $.64(.41)$ & \\
\hline
\end{tabular}


Table 6

Mediation Analyses

\begin{tabular}{|c|c|c|c|c|}
\hline Dependent Variable & Independent Variable & $R^{2}$ & $B$ & $(S E)$ \\
\hline \multicolumn{5}{|c|}{ 3-step test for mediation with Cognitive Interference (Frequency) } \\
\hline 1. Performance & Experimental Manipulation & $.13 * *$ & $9.75 * *$ & $(2.83)$ \\
\hline 2. Cognitive Interference (Frequency) & Experimental Manipulation & $.11 * *$ & $-.41 * *$ & $(.14)$ \\
\hline \multirow[t]{2}{*}{ 3. Performance } & Cognitive Interference (Frequency) & $.15 * *$ & -3.26 & $(2.34)$ \\
\hline & Experimental Manipulation & & $8.40^{*}$ & $(2.97)$ \\
\hline \multicolumn{5}{|c|}{ 3-step test for mediation with Cognitive Interference (Distraction) } \\
\hline 1. Performance & Experimental Manipulation & $.13^{* *}$ & $9.75 * *$ & $(2.83)$ \\
\hline 2. Cognitive Interference (Distraction) & Experimental Manipulation & $.10^{*}$ & $-.37^{*}$ & $(.13)$ \\
\hline \multirow[t]{2}{*}{ 3. Performance } & Cognitive Interference (Distraction) & $.13 * *$ & .09 & $(2.57)$ \\
\hline & Experimental Manipulation & & $9.78 * *$ & $(3.00)$ \\
\hline
\end{tabular}

Note. $N=80 .{ }^{*} p<.05,{ }^{* *} p<.01$ 


\section{Figure Caption}

Figure 1. The interaction of perceived support and the experimental manipulation in relatio putting scores. 


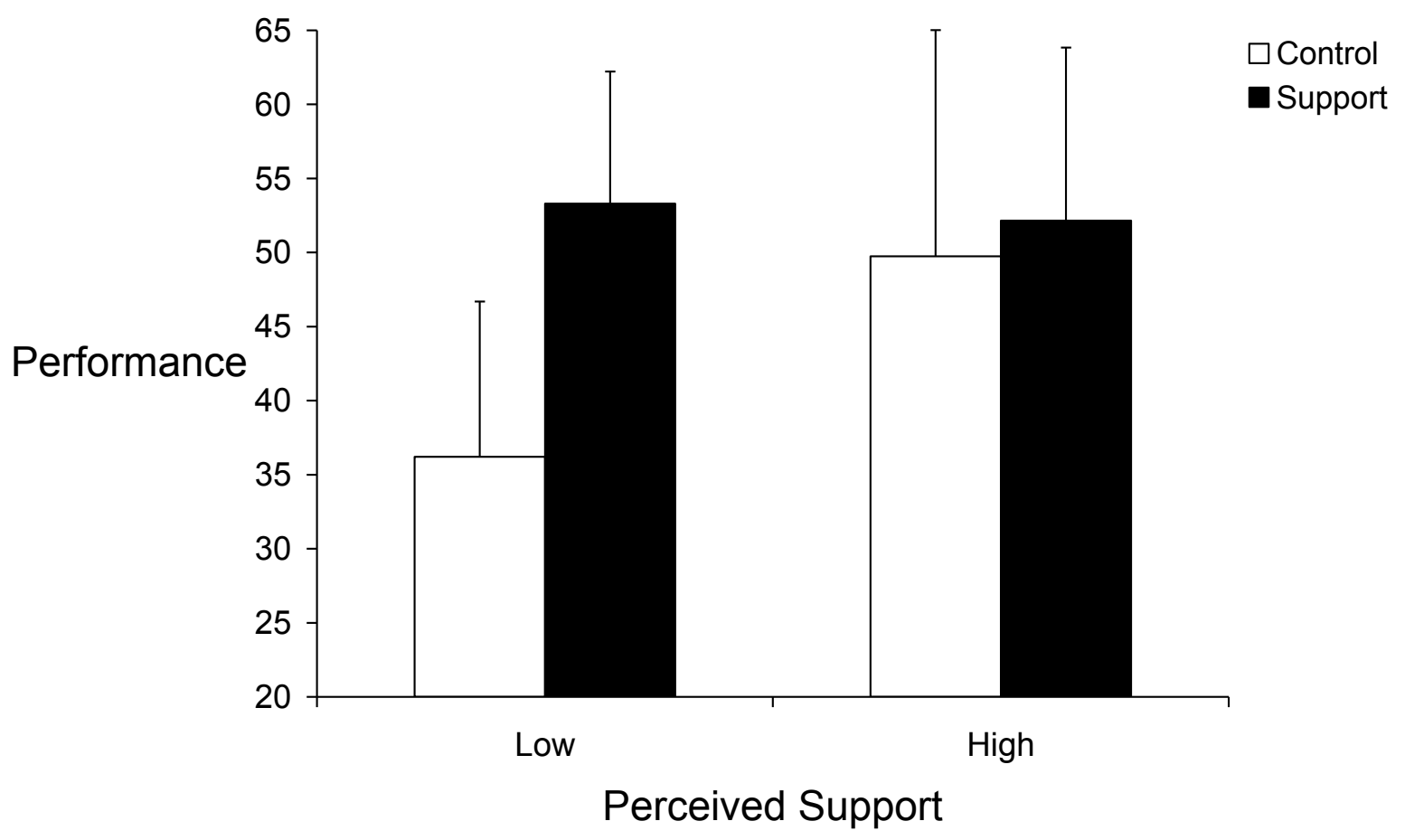

